\title{
Multiobjective Optimization of Tool Geometric Parameters Using Genetic Algorithm
}

\author{
Maohua Du (D), Zheng Cheng $(\mathbb{D}$, Yanfei Zhang $(\mathbb{D}$, and Shensong Wang $\mathbb{D}$ \\ Department of Mechanical Engineering, Kunming University of Science and Technology, Kunming 650500, China \\ Correspondence should be addressed to Maohua Du; 1337289843@qq.com
}

Received 10 July 2018; Accepted 11 September 2018; Published 1 November 2018

Guest Editor: Liang $\mathrm{Hu}$

Copyright ( 2018 Maohua Du et al. This is an open access article distributed under the Creative Commons Attribution License, which permits unrestricted use, distribution, and reproduction in any medium, provided the original work is properly cited.

\begin{abstract}
Tool geometric parameters have a huge impact on tool wear. Up to now, there are only a few researches on tool geometric parameters and optimization, and the single objective function of parameter optimization used by researchers during high-speed machining (HSM) mainly is the minimum cutting force. However, the elevated cutting temperature also greatly affects tool wear due to the numerous cutting heat generation. Thus, to reduce tool wear, it is the most fundamental approach to taking into account the comprehensive control of the cutting force and cutting temperature because they are the two most important physical quantities in metal cutting processes. This work proposes a new optimization idea of the cutting-tool's multi geometric parameters (three main parameters: rake angle, clearance angle, and cutting edge radius) with two objective functions (the cutting force and the temperature). Based on the response surface method (RSM), we have established the modified functional relation models of the influence of tool geometric parameters on the cutting force and temperature according to the finite element simulation results in high-speed cutting of Ti6Al4V. Then the models are solved by using a genetic algorithm, and the optimal tool geometric parameters values that can concurrently control the two objectives in their minimum values are obtained. The advantages lie in the strategy of the separate models of the cutting force and cutting temperature owing to their different dimensions and the solution of the models through giving the cutting force and cutting temperature different weight coefficients. The optimal results are verified by experiments, which shows that the optimal tool geometric parameters are very effective and vital for ensuring both the cutting force and the cutting temperature not too high. This work is of great significance to the cutting tool design theory and its manufacturing for reducing tool wear.
\end{abstract}

\section{Introduction}

In a metal cutting process, a cutting tool is the most direct factor affecting the cutting process. The cutting force, cutting heat, tool life, and surface quality of the workpiece are closely related to the tool geometric parameters. Ai et al. [1] pointed out that the tool geometric parameters have a tremendous influence on the tool durability. Denkena and Biermann [2] believed that tool life and performance are decisively determined by cutting edge geometry. On the premise of some fixed factors such as machine tools, cutting tool material, workpiece material, and cutting parameters, tool geometric parameters will influence the cutting performance of the cutting tool, prolong tool life, and greatly improve productivity.
Up to now, there are only a few researches on tool geometric parameters and optimization of high-speed machining (HSM), and the single objective function of parameter optimization for reducing tool wear used by researchers mainly is the minimum cutting force. Lo [3] conducted cutting simulations under different tool rake angles to explore the effect of the tool rake angle on cutting force in machining of oxygen-free high conductivity copper (OFHC). The findings indicate that an increase in the tool rake angle leads to a decrease in the cutting force and the cutting-force reduction is most evident as the rake angle increases from $10^{\circ}$ to $15^{\circ}$. Wyen and Wegener [4] investigated the influence of the cutting edge radius on cutting forces in machining titanium, and the results show that the cutting force components increase with the increase of rounded cutting edges. 
However, tool geometry involves more than one, such as other basic and important tool angles including the rake angle and clearance angle, so we need to further deal with cutting-tool's multi parameter problems. Saglam et al. [5] studied the effect of rake angle and approaching angle (main cutting edge angle) on the main cutting force and tool tip temperature while machining AISI 1040 steel hardened at HRC 40 and found that the optimum approaching angle is $75^{\circ}$ and the rake angle is $12^{\circ}$ by considering the cutting force and temperature together. This conclusion is meaningful and referable for the research of metal cutting principle, but since the cutting process is quite complicated, the absence of the clearance angle will significantly affect the magnitudes of the cutting force and cutting zone temperature. It is necessary to explore the comprehensive influence of tool's multi geometric parameters on the cutting force and temperature in the cutting process. Sultan and Okafor [6] investigated the effects of four geometric parameters (the wavelength, wave magnitude, axial shift of the linear part, and the helix angle of the wavy cutting edges) of wavy-edge bull-nose helical end-mill (WEBNHE) on cutting force prediction in endmilling. As far as the helix angle of the cutting edge is concerned, the result shows that increasing the helix angle of the wavy cutting edges of the WEBNHE from $25^{\circ}$ to $30^{\circ}$ will decrease the magnitudes and ranges of the cutting force components $F_{\mathrm{y}}$ (in the feed direction) and $F_{\mathrm{x}}$ (radial direction) and the resultant cutting force $F_{\mathrm{R}}$, but does not affect the cutting force component $\mathrm{Fz}$ (axial direction) significantly. And increasing the helix angle from $30^{\circ}$ to $35^{\circ}$ will not significantly affect any cutting force components. This indicates that the helix angle has an optimal value that needs further study. It was found by Kountanya et al. [7] that edge radius did not alter the chip geometry during hard turning of 100Cr6 (HRC60) but machining forces decreased with the increase of cutting speed and chip formation frequency. Bouzakis et al. [8] obtained that a cutting performance in milling Inconel 718 and Ti6Al4V is improved by increasing the wedge radius because of a significant cutting edge load reduction. However, it is expected to give more attention and further study on the effect of edge rounding on the cutting processes.

In respect of the tool geometric parameter optimization, Pan et al. [9] studied on the optimization of one tool geometric parameter (helix angle of end milling tool) and cutting parameters (axial and radial depth of cut) for high-speed milling aviation aluminum alloy with minimum cutting force as a single objective function. This work depicted that when axial and radial depth of cut were in the ranges of 5-7 mm and $3-5 \mathrm{~mm}$, respectively, the helix angle of end milling tool between $35^{\circ}$ and $40^{\circ}$ could acquire a minimum cutting force. Wan et al. [10] studied the working mechanism of peripheral milling tool's helix angle on peak cutting force through strict analytical formulation. The conclusion is that the optimal helix angle corresponding to the minimum peak cutting force can be designed according to the axial depth of cut, the number of flutes, and the diameter of the milling cutter. Mia et al. [11] explored the optimization of the minimum quantity lubrication (MQL) flow rate for the minimum cutting force and surface roughness in end milling of hardened steel
(HRC40), and the grey-based Taguchi method suggested that a flow rate of $150 \mathrm{ml} / \mathrm{h}$ ensures the minimum cutting force and surface roughness. But the complex relation between the cutting force and the surface roughness is yet hardly defined and the attention needs to be paid by researchers in a future work.

It is noteworthy that in a high-speed machining process, when the cutting force is the minimum, the tool wear degree is not necessarily in direct proportion to it. Narutaki [12] investigated the change rule of cutting temperature and cutting force in the turning of the titanium alloy Ti6Al4V in the speed range of $20-200 \mathrm{~m} / \mathrm{min}$. It is found that at this range the change of cutting force is not significant with the increase of the cutting speed, but the cutting temperature is very high and even exceeds $1000^{\circ} \mathrm{C}$ at the speed of $200 \mathrm{~m} / \mathrm{min}$. This indicates that the cutting temperature is the main reason of cutting tool wear.

A considerable research effort has been made on the cutting temperature in metal cutting. Abukhshim et al. [13] stated that high cutting temperatures strongly influence tool wear and contribute to the thermal deformation of the cutting tool. Jiang et al. [14] hold that cutting temperature is a key factor which directly affects tool wear, so they conducted the analytical modeling of tool and workpiece temperatures and experimental investigation in the interrupted cutting of 1045 steel. The results showed that there exists a critical cutting speed for the workpiece temperature and tool insert temperature, respectively, and the peak temperature of the workpiece appears at $1500 \mathrm{~m} / \mathrm{min}$, while the peak tool insert temperature appears at $1250 \mathrm{~m} / \mathrm{min}$ approximately. Xie et al. [15] experimentally studied the cutting temperature and cutting force in dry turning of titanium alloy using tools with microgrooves on the rake face, and it is shown that microgrooves on the tool rake surface contribute to the decrease of cutting temperature by $103^{\circ} \mathrm{C}$ and more against a traditional plane tool. And the $25 \mu \mathrm{m}$ depth microgrooved tool decreases cutting temperature and cutting force more greatly in larger material removal rate of turning.

Shaw [16] presented (1) of the cutting temperature as follows:

$$
q \approx E_{c} \sqrt{\frac{v d}{\lambda \rho c}}
$$

where $E_{c}$ is the specific cutting energy; $v$ is the cutting speed; $d$ is uncut chip thickness; and $\lambda, \rho$, and $c$ are the thermal conductivity, density, and specific heat of the workpiece material, respectively.

Since both the density $\rho$ and thermal conductivity $\lambda$ of Ti6Al4V material are much smaller among the metallic materials, $\rho=4.43 \mathrm{~g} / \mathrm{cm}^{3}$ (by contrast, the density of iron is $7.87 \mathrm{~g} / \mathrm{cm}^{3}$ ), $\lambda=6.8 \mathrm{~W} / \mathrm{m} \cdot \mathrm{K}$ (at the temperature of $20^{\circ} \mathrm{C}$ ) (for iron, $\lambda=76.2 \mathrm{~W} / \mathrm{m} \cdot \mathrm{K}$ ), and $c=0.5263 \mathrm{~J} / \mathrm{g} \cdot{ }^{\circ} \mathrm{C}$ (for iron, $\left.c=0.44 \mathrm{~J} / \mathrm{g} \cdot{ }^{\circ} \mathrm{C}\right)$. So Ti6Al4V material has very large $(\lambda \rho c)^{-1 / 2}$. This means that the cutting temperature in machining of Ti6Al4V can be very high. Therefore, the cutting temperature is an indispensible aspect when we study the cutting process of titanium alloy Ti6Al4V. 
From the above literature, we know that the cutting force and the cutting temperature are two important physical quantities which are independent and interact with each other. The cutting force directly affects the generation of the cutting heat, and in turn, the cutting heat affects the cutting temperature. When the cutting temperature is high, the thermal softening of the workpiece material will occur and the cutting force will decrease. Meanwhile, tool materials may diffuse to the workpiece, which will cause chemical wear of the tool and shorten the tool life. Thus, to prolong the tool life in highspeed machining of difficult-to-cut materials, only the cutting force and the cutting temperature are considered together and control both within their optimum values, respectively, can the cutting ability of the cutting tool be ensured.

Therefore, the purpose of this work is to study the multiobjective optimization of cutting-tool's multi geometric parameters (rake angle, clearance angle, and cutting edge radius of cutting tool) in high-speed machining of Ti6Al4V. Taking cutting force and cutting temperature as multiobjective functions, functional relations of the influence of tool geometric parameters on the cutting force and cutting temperature using response surface method (RSM) are established based on finite element (FE) simulation results of high-speed cutting of Ti6Al4V under different levels of cutting tool geometric parameters. Then the optimized tool geometric parameters are calculated, such that both the cutting force and temperature are concurrently controlled.

\section{FE Simulation of High-Speed Cutting of Ti6Al4V}

During the cutting process, the workpiece material undergoes severe plastic deformation, and the process is characterized by "three highs," that is, a high temperature which results in thermal softening of the material and high strain and high strain rate which cause the material hardening. Hence, it is a process with a thermal-mechanical coupling effect. The twodimensional orthogonal cutting model that considers this effect is established by using professional cutting simulation software AdvantEdge, illustrated in Figure 1. The workpiece is a rectangle, which is $5 \mathrm{~mm}$ in length and $2 \mathrm{~mm}$ in width, and the workpiece is set as a deformable body. For the cutting tool, we only focus on its force and the heat situation without considering the deformation, so it is assumed to be a rigid body. The adaptive triangular mesh element is used. In the cutting process, the workpiece is fixed and the cutting tool moves horizontally from the right to the left.

Since Johnson-Cook (J-C) empirical constitutive model takes into account the work hardening, strain rate hardening, and thermal softening of the workpiece material during highspeed cutting, J-C failure model can be used not only as the chip separation criterion but also as its fracture model. Therefore, the J-C material constitutive model and J-C failure model are adopted, which are represented in (2) and (3), respectively.

$$
\bar{\sigma}=\left[A+B\left(\bar{\varepsilon}^{\mathrm{pl}}\right)^{n}\right]\left[1+C \ln \left(\frac{\dot{\bar{\varepsilon}}^{\mathrm{pl}}}{\dot{\varepsilon}_{0}}\right)\right]\left\{1-\left[\frac{T-T_{0}}{T_{\text {melt }}-T_{0}}\right]^{m}\right\}
$$

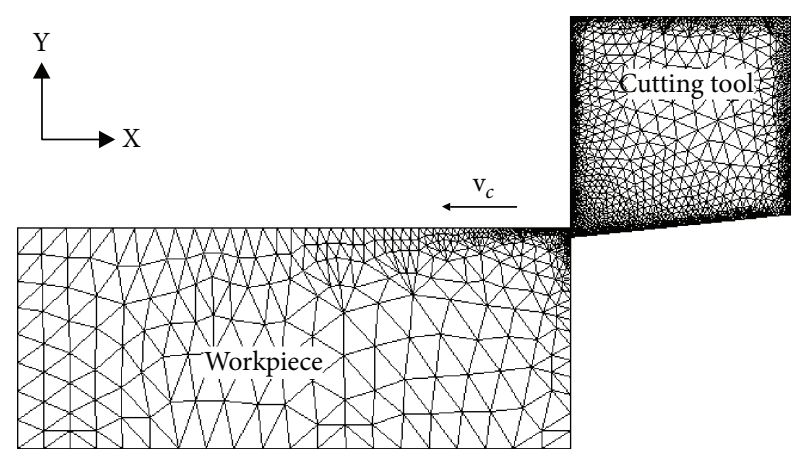

FIGURE 1: FE simulation model.

TABLE 1: J-C constitutive parameters for Ti6Al4V alloy.

\begin{tabular}{lccccc}
\hline Material & $A(\mathrm{Mpa})$ & $B(\mathrm{Mpa})$ & $n$ & $m$ & $C$ \\
\hline Ti6Al4V & 782 & 498 & 0.28 & 1 & 0.028 \\
\hline
\end{tabular}

TABLE 2: J-C failure parameters for Ti6Al4V [18].

\begin{tabular}{ccccc}
\hline$d_{1}$ & $d_{2}$ & $d_{3}$ & $d_{4}$ & $d_{5}$ \\
\hline-0.09 & 0.25 & -0.5 & 0.014 & 3.87 \\
\hline
\end{tabular}

where $\bar{\sigma}$ is the flow stress, $\overline{\mathcal{\varepsilon}}^{\mathrm{pl}}$ the equivalent plastic strain; $\overline{\bar{\varepsilon}}^{\mathrm{pl}}$ the equivalent plastic strain rate $\left(s^{-1}\right)$, and $\dot{\varepsilon}_{0}$ the reference plastic strain rate $\left(s^{-1}\right)$. Coefficient $A(\mathrm{MPa})$ is the yield strength, $B(\mathrm{MPa})$ the hardening modulus, $C$ the strain rate sensitivity coefficient, $n$ the hardening coefficient, and $m$ the thermal softening coefficient. $T\left({ }^{\circ} \mathrm{C}\right)$ is the work temperature, $T_{\text {melt }}$ is the melting temperature of the work material, and $\mathrm{T}_{0}\left(20^{\circ} \mathrm{C}\right)$ is the room temperature.

$$
\begin{aligned}
\bar{\varepsilon}_{f}^{\mathrm{pl}}= & {\left[d_{1}+d_{2} \exp \left(\frac{d_{3} \sigma_{n}}{\sigma_{\text {Mise }}}\right)\right]\left[1+d_{4} \ln \left(\frac{\dot{\bar{\varepsilon}}^{\mathrm{pl}}}{\dot{\varepsilon}_{0}}\right)\right] } \\
& \cdot\left[1+d_{5} \frac{\left(T-T_{0}\right)}{\left(T_{\text {melt }}-T_{0}\right)}\right],
\end{aligned}
$$

where $\bar{\varepsilon}_{f}^{\mathrm{pl}}$ is the failure plastic strain for damage initiation, $d_{1} \sim d_{5}$ are failure parameters which can be determined by experiments, $\sigma_{n}$ is the pressure stress, $\sigma_{\text {Mise }}$ is the Mises stress, and $\dot{\bar{\varepsilon}}^{\mathrm{pl}}$ and $\dot{\varepsilon}_{0}$ are defined above in (2).

The parameters of the J-C constitutive model and failure model for Ti6Al4V are listed in Table 1 (Lee and Lin [17]) and Table 2, respectively.

The thermodynamic parameters of $\mathrm{Ti} 6 \mathrm{Al} 4 \mathrm{~V}$ are as follows: hardness HB 320; Young's modulus 108 (Gpa); Poisson's ratio 0.33; shear strength 760 (Mpa); yielding strength 860 (Mpa); specific heat $526.3(\mathrm{~J} / \mathrm{kg})$; thermal conductivity $6.8(\mathrm{~W} / \mathrm{m} \cdot \mathrm{K})\left(20^{\circ} \mathrm{C}\right), 8.7\left(200^{\circ} \mathrm{C}\right)$, and 11.8 $\left(500^{\circ} \mathrm{C}\right)$; linear expansion rate $9.1 E-6(\mathrm{~m} / \mathrm{m})\left(20^{\circ} \mathrm{C}\right), 9.2 E$ $-6\left(250^{\circ} \mathrm{C}\right)$, and $9.7 \mathrm{E}-6\left(500^{\circ} \mathrm{C}\right)$; and melting point 1650 $\left({ }^{\circ} \mathrm{C}\right)$. The thermodynamic parameters for carbide cutting tool 
TABLE 3: Cutting tool geometric parameters.

\begin{tabular}{lccc}
\hline Level & $\begin{array}{c}\text { Rake angle } \\
\gamma_{o}\left({ }^{\circ}\right)\end{array}$ & $\begin{array}{c}\text { Clearance angle } \\
\alpha_{o}\left({ }^{\circ}\right)\end{array}$ & $\begin{array}{c}\text { Cutting edge radius } \\
r_{\varepsilon}(\mathrm{mm})\end{array}$ \\
\hline 1 & 0 & 2 & 0.01 \\
2 & 5 & 4 & 0.04 \\
3 & 10 & 6 & 0.07 \\
4 & 15 & 8 & 0.1 \\
5 & 20 & 10 & 0.13 \\
\hline
\end{tabular}

are as follows: Young's modulus 640 (Gpa); Poisson's ratio 0.22 ; linear expansion rate $4.5 E-6(\mathrm{~m} / \mathrm{m})$; specific heat $220(\mathrm{~J} / \mathrm{kg})$; and thermal conductivity $75.4(\mathrm{~W} / \mathrm{m} \cdot \mathrm{K})$.

The friction coefficient $\mu$ between the tool and the workpiece is taken as $\mu=0.45$, which is obtained by calculations; the initial temperature of the cutting system is set as $20^{\circ} \mathrm{C}$.

2.1. Scheme of Orthogonal Cutting Simulations. To study the influence of tool geometric parameters on the cutting force and cutting temperature, tool geometric parameters should be variables, and the three factor-five level orthogonal experimental scheme is designed, as presented in Table 3. The cutting speed $v_{c}$ and the feed rate $f$ are fixed values: $v_{c}=122.5 \mathrm{~m} / \mathrm{min}$ and $f=0.085 \mathrm{~mm} / \mathrm{rev}$, respectively. They are the maximum speed and the maximum feed rate that the cutting tool has cutting ability according to the corresponding specifications of the lathe used in the experiments (see Section 5).

\subsection{FE Simulation Results of the Chip Shape and Cutting} Force. Table 4 presents the orthogonal array of tool geometric parameters based on the experimental conditions in Table 3 by using Taguchi's method, because it is difficult to graphically display the variation trend of multiobjectives with the concurrent changes of three parameters. Therefore, we study the influence laws of the single parameter on single objective first and then combine them to describe the complex relations with mathematical models.

In Table $4, F_{x}$ is simulated main cutting force; $F_{y}$ simulated thrust force; $F$ simulated total cutting force; $\widehat{F}$ predicted cutting force by the optimization model; $\varepsilon_{F}$ cutting force prediction error; $T$ simulated cutting temperature; $\widehat{T}$ predicted cutting temperature by the optimization model; $\varepsilon_{T}$ cutting temperature prediction error.

During high-speed machining of Ti6Al4V, serrated chips are always obtained under various different cutting conditions, and all finite element simulations show that when two of tool geometric parameters keep unchanged, the variation trends of cutting forces and cutting temperatures are almost the same with the change of the remaining one. Therefore, we give only one typical case of all simulation results, shown in Figures 2, 3, 4, 5, and 6, respectively. Figures 2-4 show the simulated chip shapes at different geometric parameters. The simulated cutting forces in a steady state are listed in Table 4.

As can be seen from Figure 2, the serrated degrees of the chip vary significantly with the change of the rake angle, and the small rake angle will increase the serrated degree. It can be seen from Figure 3 that when other conditions keep unchanged $\left(\gamma_{o}=10^{\circ}, r_{\varepsilon}=0.07 \mathrm{~mm}\right)$, the chip shapes have a little change at different clearance angles. Figure 4 shows that the larger the cutting edge radius is, the more obvious the saw-tooth phenomenon is. The saw-tooth chip will result in high-frequency periodic vibration of the machine tools, hence cause cutting force change periodically. As a result, the tool wear increases.

Figure 5 illustrates the change trend of cutting forces at different tool geometric parameters under single factor condition (one parameter varies, and the others remain unchanged). Figure 5(a) shows that main cutting force $F_{x}$, thrust force $F_{y}$, and total cutting force $F$ have the same decrease trend with the increase of the rake angle $\gamma_{o}$. This is because the tooltip becomes sharp and the cutting becomes easy when $\gamma_{o}$ increases. Also, the total force has a linear relationship with $\gamma_{o}$. It can be seen from Figure 5(b) that the main cutting force $F_{x}$ has no obvious change when the clearance angle $\alpha_{o}$ increases from $2^{\circ}$ to $10^{\circ}$ and the thrust force $F_{y}$ is greatly influenced by $\alpha_{o}$. With the increase of $\alpha_{o}$, $F_{y}$ decreases obviously. The total cutting force $F$ varies slowly with the increase of $\alpha_{o}$, and there is a linear relationship between them. The role of the cutting edge radius is to increase the strength of the tooltip that is directly involved in cutting. Figure 5(c) shows that $F_{x}, F_{y}$, and $F$ increase with the increase of the cutting edge radius $r_{\varepsilon}$ and $F_{y}$ is the most affected by $r_{\varepsilon}$. It can be seen that $F$ basically has a quadratic relation with $r_{\varepsilon}$.

2.3. FE Simulation Results of the Cutting Temperature. The cutting tool directly cuts the material, and its geometric parameters are the important factors that affect the cutting temperature. The simulated average cutting temperature results at a steady state are presented in Table 4. Figure 7 shows the temperature field distributions at a given cutting condition $\left(\gamma_{o}=15^{\circ}, \alpha_{o}=10^{\circ}\right.$, and $\left.r_{\varepsilon}=0.07 \mathrm{~mm}\right)$. From Figure 7 , we can see that the highest cutting temperature is distributed near the tooltip.

Figures 6(a)-6(c) show the simulated cutting temperatures at different geometric parameters under a single factor condition.

From Figure 6(a), we can see that the temperatures of the chip and the machined surface decrease with the increase of the tool rake angle. This is because during the cutting process, the increase of the tool rake angle makes the cutting tool sharp and the metal deformation of the cutting layer decreases; thus, the heat generation reduces. In Figure 6(b), the temperatures decrease as the clearance angle increases. This is because the increase of the tool clearance angle can reduce the contact length between the tool flank and the machined surface, and the contact friction becomes small and the corresponding heat generation goes down. However, when the tool clearance angle increases to a certain degree $\left(\alpha_{o}>6^{\circ}\right)$, the influence of the contact length will weaken. Figure 6(c) shows the temperatures increase with the increase of the cutting edge radius. This is directly related to the blunt cutting edge, which causes the increase of heat generation. It can also be seen that when $r_{\varepsilon}>0.1 \mathrm{~mm}$, the temperature 
TABLE 4: Simulated and predicted results in high-speed cutting of Ti6Al4V.

\begin{tabular}{|c|c|c|c|c|c|c|c|c|c|c|c|}
\hline \multirow{2}{*}{ No. } & \multicolumn{3}{|c|}{ Combination } & \multicolumn{4}{|c|}{ Simulated results } & \multicolumn{2}{|c|}{ Predicted results } & \multicolumn{2}{|c|}{ Errors } \\
\hline & $\gamma_{o}\left({ }^{\circ}\right)$ & $\alpha_{o}\left({ }^{\circ}\right)$ & $r_{\varepsilon} / \mathrm{mm}$ & $F_{x} / \mathrm{N}$ & $F_{y} / \mathrm{N}$ & $F / \mathrm{N}$ & $T /{ }^{\circ} \mathrm{C}$ & $\widehat{F} / \mathrm{N}$ & $\widehat{T} /{ }^{\circ} \mathrm{C}$ & $\varepsilon_{F} / \%$ & $\varepsilon_{T} / \%$ \\
\hline 1 & 0 & 2 & 0.01 & 606 & 250 & 655.5 & 548 & 652.2 & 599.7 & 0.5 & 9.4 \\
\hline 2 & 0 & 4 & 0.04 & 565 & 321 & 649.8 & 568 & 632 & 602.5 & 2.7 & 6.08 \\
\hline 3 & 0 & 6 & 0.07 & 555 & 402 & 682.8 & 655 & 657.8 & 621.7 & 3.6 & 5.08 \\
\hline 4 & 0 & 8 & 0.1 & 543 & 503 & 740 & 630 & 729.5 & 657.3 & 1.4 & 4.33 \\
\hline 5 & 0 & 10 & 0.13 & 574 & 606 & 834.6 & 670 & 847.2 & 709.1 & 1.5 & 5.84 \\
\hline 6 & 5 & 2 & 0.04 & 521 & 290 & 596 & 620 & 622.8 & 609 & 4.5 & 1.77 \\
\hline 7 & 5 & 4 & 0.07 & 537 & 400 & 669 & 700 & 649.6 & 622.2 & 2.9 & 11.11 \\
\hline 8 & 5 & 6 & 0.1 & 534 & 490 & 724 & 635 & 722.3 & 651.8 & 0.2 & 2.64 \\
\hline 9 & 5 & 8 & 0.13 & 575 & 602 & 832 & 780 & 841 & 697.6 & 1.08 & 10.56 \\
\hline 10 & 5 & 10 & 0.01 & 569 & 220 & 610 & 625 & 616.2 & 609 & 1.01 & 2.55 \\
\hline 11 & 10 & 2 & 0.07 & 510 & 374 & 632 & 670 & 644.9 & 633.9 & 2.05 & 5.38 \\
\hline 12 & 10 & 4 & 0.1 & 529 & 489 & 720 & 640 & 718.7 & 657.4 & 0.18 & 2.73 \\
\hline 13 & 10 & 6 & 0.13 & 558 & 561 & 791 & 710 & 838.4 & 697.3 & 6 & 1.78 \\
\hline 14 & 10 & 8 & 0.01 & 563 & 204 & 598.8 & 595 & 600.5 & 583.7 & 0.28 & 1.9 \\
\hline 15 & 10 & 10 & 0.04 & 513 & 247 & 569 & 575 & 588.4 & 616.6 & 3.5 & 7.23 \\
\hline 16 & 15 & 2 & 0.1 & 521 & 475 & 705 & 710 & 718.7 & 674.4 & 1.95 & 5.01 \\
\hline 17 & 15 & 4 & 0.13 & 582 & 621 & 851 & 690 & 839.5 & 708.3 & 1.35 & 2.65 \\
\hline 18 & 15 & 6 & 0.01 & 530 & 177 & 558 & 600 & 588.4 & 569.6 & 5.4 & 5.07 \\
\hline 19 & 15 & 8 & 0.04 & 493 & 253 & 554 & 520 & 577.7 & 596.4 & 4.3 & 14.7 \\
\hline 20 & 15 & 10 & 0.07 & 502 & 373 & 625 & 660 & 613 & 639.6 & 1.9 & 3.08 \\
\hline 21 & 20 & 2 & 0.13 & 566 & 587 & 815 & 700 & 844.1 & 730.5 & 3.6 & 4.35 \\
\hline 22 & 20 & 4 & 0.01 & 497 & 152 & 519 & 570 & 579.9 & 566.7 & 11.73 & 0.59 \\
\hline 23 & 20 & 6 & 0.04 & 504 & 286 & 579 & 601 & 570.2 & 587.5 & 1.52 & 2.08 \\
\hline 24 & 20 & 8 & 0.07 & 550 & 324 & 595 & 639 & 606.5 & 624.8 & 1.93 & 2.23 \\
\hline 25 & 20 & 10 & 0.1 & 530 & 487 & 719 & 656 & 688.7 & 678.3 & 4.22 & 3.4 \\
\hline
\end{tabular}

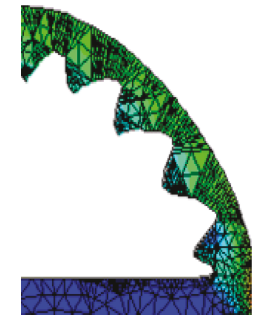

(a) $\gamma_{o}=0^{\circ}$

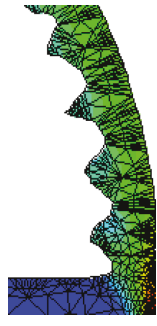

(b) $\gamma_{o}=5^{\circ}$

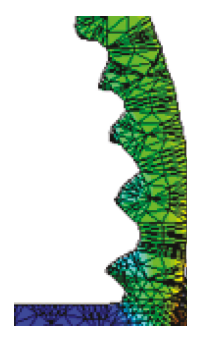

(c) $\gamma_{o}=10^{\circ}$

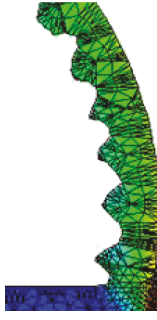

(d) $\gamma_{o}=15^{\circ}$

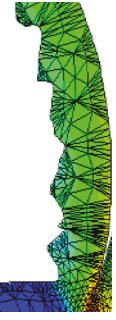

(e)

FIGURE 2: Chip shapes at different rake angles $\left(\alpha_{o}=6^{\circ}, r_{\varepsilon}=0.07 \mathrm{~mm}\right)$.

curves become flat and even show a declining trend, which is due to the increase of the heat dissipation volume of the tool tip or the improved heat dissipation condition in the cutting zone.

\section{The Establishment of Mathematical Model for Tool Geometric Parameter Optimization}

In metal cutting simulation, the flow stress behavior of the workpiece material in the cutting region and the friction at the tool-chip interface are the two main factors, which are described by Childs et al. [19] and Ozel [20]; among these, the constitutive parameters of the workpiece material have been determined by experiments (Table 1), and the friction coefficient at the tool-chip interface is derived through our previous study related to this work by using FE analysis and experiments. Therefore, we can preliminarily believe that to a certain degree the above FE modeling and analysis results in this work are correct. (To reduce the experiments and the cutting tool sharpening, the verification experiments of the FE model will be 


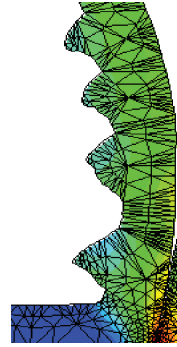

(a) $\alpha_{o}=2^{\circ}$

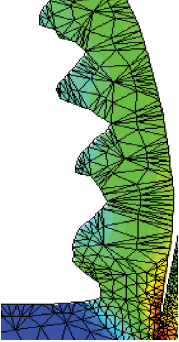

(b) $\alpha_{o}=4^{\circ}$

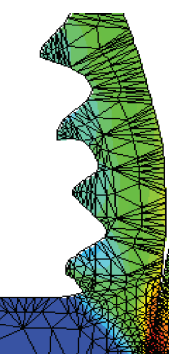

(c) $\alpha_{o}=6^{\circ}$

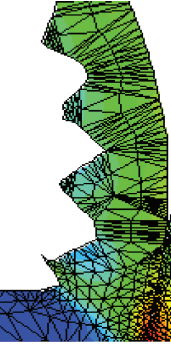

(d) $\alpha_{o}=8^{\circ}$

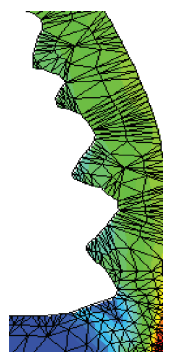

(e) $\alpha_{o}=10^{\circ}$

FiguRE 3: Chip shapes at different clearance angles $\left(\gamma_{o}=10^{\circ}, r_{\varepsilon}=0.07 \mathrm{~mm}\right)$.

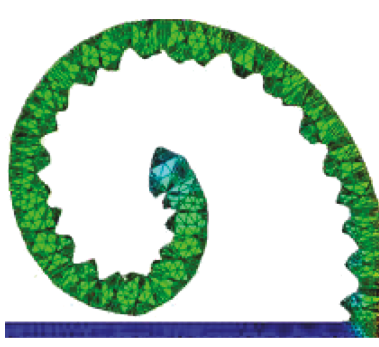

(a) $r_{\varepsilon}=0.01 \mathrm{~mm}$

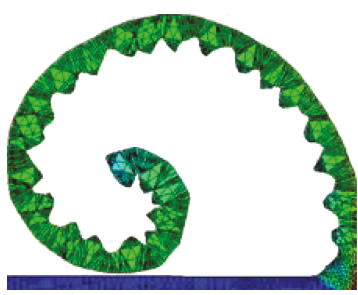

(b) $r_{\varepsilon}=0.04 \mathrm{~mm}$

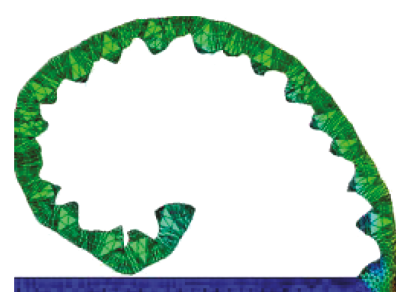

(c) $r_{\varepsilon}=0.07 \mathrm{~mm}$

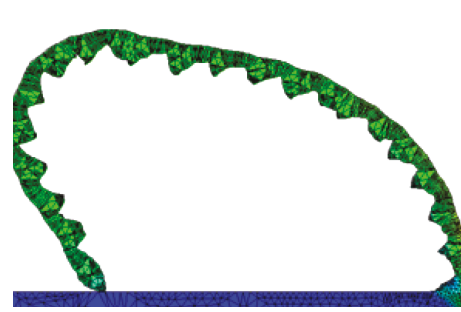

(d) $r_{\varepsilon}=0.10 \mathrm{~mm}$

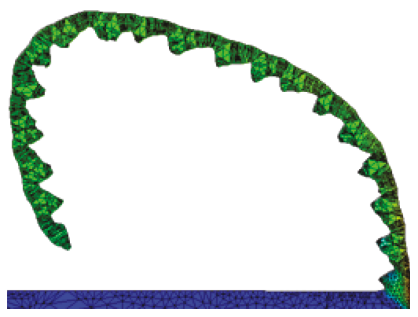

(e) $r_{\varepsilon}=0.13 \mathrm{~mm}$

FIgURE 4: The chip shape at different cutting edge radii $\left(\gamma_{o}=10^{\circ}, \alpha_{o}=6^{\circ}\right)$.

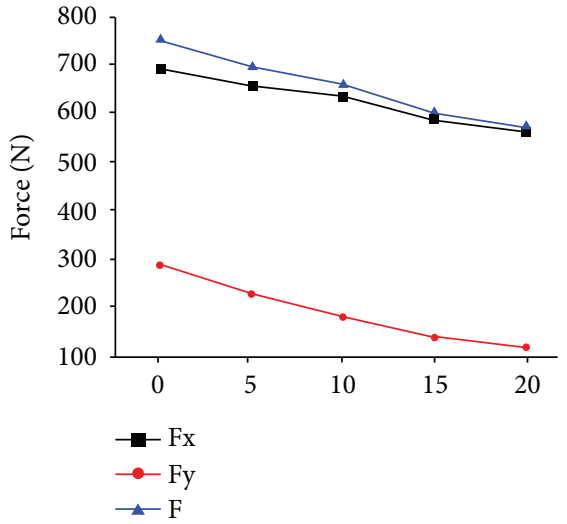

(a) Rake angle $\gamma_{o}\left({ }^{\circ}\right)$

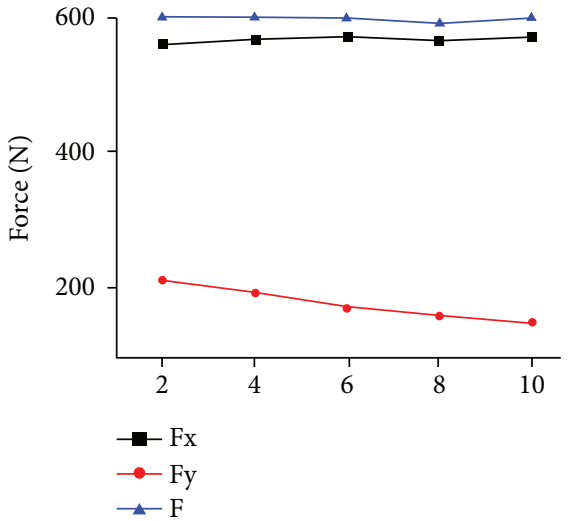

(b) Clearance angle $\alpha_{o}\left({ }^{\circ}\right)$

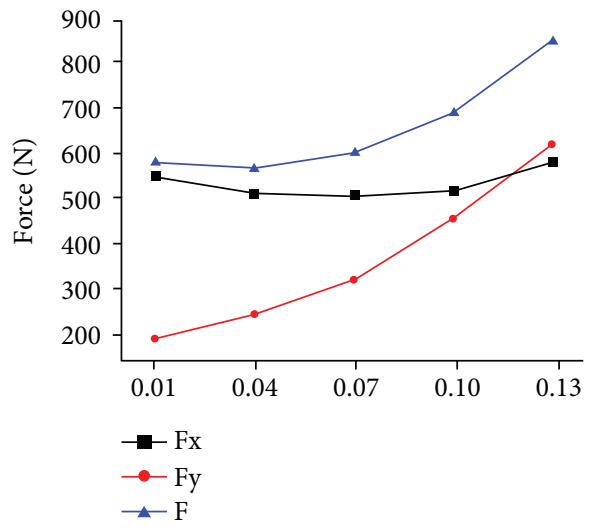

(c) Cutting edge radius $r_{\varepsilon}(\mathrm{mm})$

Figure 5: The influence of geometric parameters on cutting force: (a) at different rake angles $\left(\alpha_{o}=6^{\circ}, r_{\varepsilon}=0.07 \mathrm{~mm}\right)$; (b) at different clearance angles $\left(\gamma_{o}=10^{\circ}, r_{\varepsilon}=0.07 \mathrm{~mm}\right)$; and (c) at different cutting edge radii $\left(\gamma_{o}=10^{\circ}, \alpha_{o}=6^{\circ}\right)$.

carried out after the optimal tool geometric parameters are obtained.)

Based on simulated cutting force and cutting temperature results, we use the response surface method (RSM) to establish the mathematical model of tool geometric optimization.
3.1. Response Surface Method (RSM). The RSM is a statistical data processing method based on experimental design and a number of experimental data, which uses multivariable linear or quadratic regression equations to fit the functional relationship between the response and 


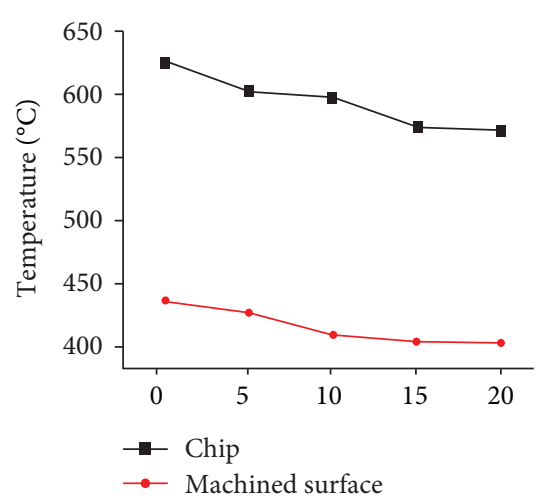

(a) Rake angle $\left(^{\circ}\right)$

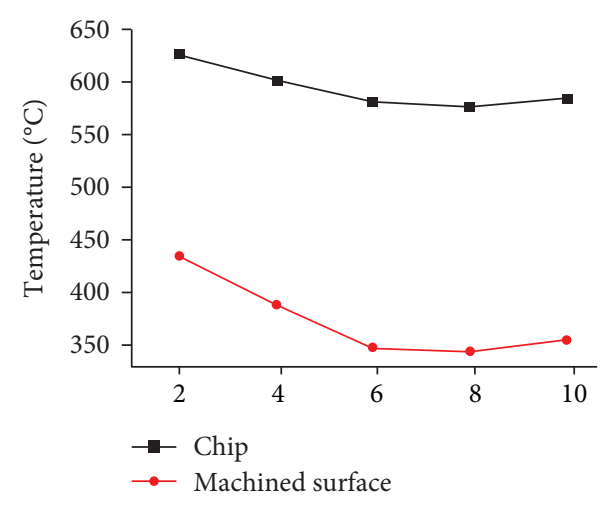

(b) Clearance angle $\alpha_{o}\left({ }^{\circ}\right)$

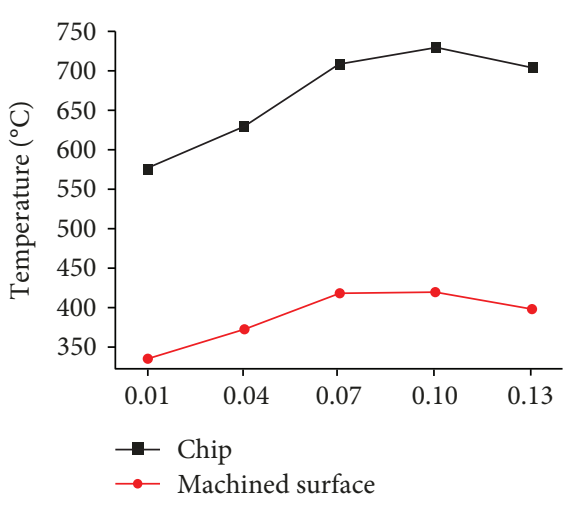

(c) Cutting edge radius $r_{\varepsilon}(\mathrm{mm})$

FIGURE 6: The influence of tool geometric parameters on cutting temperature: (a) at different rake angles $\left(\alpha_{o}=6^{\circ}, r_{\varepsilon}=0.07 \mathrm{~mm}\right)$; (b) at different clearance angles $\left(\gamma_{o}=10^{\circ}, r_{\varepsilon}=0.07 \mathrm{~mm}\right)$; and (c) at different cutting edge radii $\left(\gamma_{o}=10^{\circ}, \alpha_{o}=6^{\circ}\right)$.

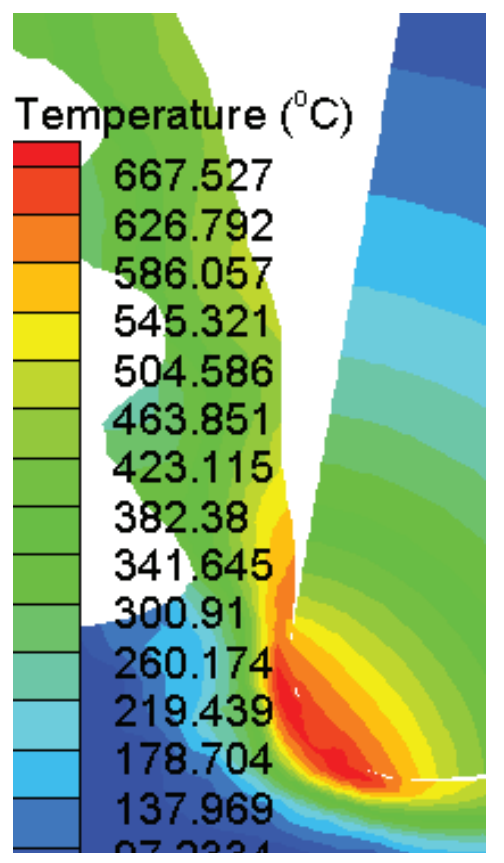

FIGURE 7: Temperature field distributions.

the experimental factors to establish a mathematical model. The response surface method finds out the relation model between the variables and the response in the way of the fitting surface. If the model is fully approximated to the actual relation, then the distribution of the fitting surface is approximately equal to the actual characteristic of the response.

Assuming there are independent experimental factors $x_{i}(i=1,2, \ldots, n)$, they have a relationship of the secondorder response surface model with the response $\hat{y}$, as presented in

$$
\widehat{y}=\beta_{0}+\sum_{i=1}^{n} \beta_{i} x_{i}+\sum_{i=1}^{n} \beta_{i i} x_{i}^{2}+\sum_{i=1}^{n} \sum_{j=1}^{k} \beta_{i j} x_{i} x_{j}+\varepsilon_{y}
$$

where $\beta_{o}$ is a constant, $\beta_{i}$ are linear term coefficients, $\beta_{i i}$ are the quadratic term coefficients, $\beta_{i j}$ are the interaction term coefficients, and $\varepsilon_{y}$ is the fitting error.

The undetermined coefficients $\beta_{0}, \beta_{1}, \ldots, \beta_{n}$ can be determined by using formula (5) based on the observed experimental data $\left(x_{11}, x_{21}, \ldots, x_{n 1}, y_{1}\right), \ldots,\left(x_{1 k}, x_{2 k}, \ldots\right.$, $\left.x_{n k}, y_{k}\right)$, and

$$
\boldsymbol{\beta}=\left[\beta_{0}, \beta_{1}, \beta_{2}, \ldots, \beta_{n}\right]^{T}=\left(\mathbf{x}^{T} \mathbf{x}\right)^{-1} \mathbf{x}^{T} \mathbf{y},
$$

where,

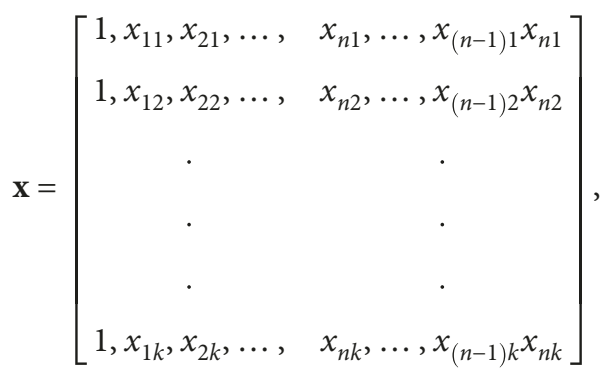

$$
\mathbf{y}=\left[\begin{array}{c}
y_{1} \\
y_{2} \\
\cdot \\
\cdot \\
y_{n}
\end{array}\right] \text {. }
$$

3.2. The Establishment of Mathematical Model of Cutting Force and Cutting Temperature. From the analysis of Figure 5, it can be seen that the relationship between the tool rake angle and the cutting force can perform linear fitting, the clearance angle has the same linear relation with the cutting force, and the cutting edge radius and the cutting force can be fitted in quadratic relation. Based on the analysis of Figure 6, the influence of the rake angle 
on temperatures has obvious linear characteristics, and the temperatures roughly display the parabolic shape with the change of the clearance angle and the cutting edge radius. Therefore, when establishing the mathematical model of cutting temperature, the rake angle should be kept linear terms, and the clearance angle and cutting edge radius should be kept quadratic terms. Thus, when the secondorder RSM is used to establish the mathematical model of the cutting force and the cutting temperature, the matrix $\mathbf{x}$ in formula (6) should be modified, as shown in formulas (7) and (8), respectively.

$\mathbf{x}_{F}=\left[\begin{array}{cccccccc}1, & \gamma_{o 1}, & \alpha_{o 1}, & r_{\varepsilon 1}, & r_{\varepsilon 1}^{2}, & \gamma_{o 1} \alpha_{o 1}, & \gamma_{o 1} r_{\varepsilon 1}, & \alpha_{o 1} r_{\varepsilon 1} \\ 1, & \gamma_{o 2}, & \alpha_{o 2}, & r_{\varepsilon 2}, & r_{\varepsilon 2}^{2}, & \gamma_{o 2} \alpha_{o 2}, & \gamma_{o 2} r_{\varepsilon 2}, & \alpha_{o 2} r_{\varepsilon 2} \\ & & & & . & & . & \\ & & & . & & . & \\ & & & & & & \\ 1, & \gamma_{o 25}, & \alpha_{o 25}, & r_{\varepsilon 25}, & r_{\varepsilon 25}^{2}, & \gamma_{o 25} \alpha_{o 25}, & \gamma_{o 25} r_{\varepsilon 25}, & \alpha_{o 25} r_{\varepsilon 25}\end{array}\right]$,

$\mathbf{x}_{T}=\left[\begin{array}{ccccccccc}1, & \gamma_{o 1}, & \alpha_{o 1}, & r_{\varepsilon 1}, & \alpha_{o 1}^{2}, & r_{\varepsilon 1}^{2}, & \gamma_{o 1} \alpha_{o 1}, & \gamma_{o 1} r_{\varepsilon 1}, & \alpha_{o 1} r_{\varepsilon 1} \\ 1, & \gamma_{o 2}, & \alpha_{o 2}, & r_{\varepsilon 2}, & \alpha_{o 2}^{2}, & r_{\varepsilon 2}^{2}, & \gamma_{o 2} \alpha_{o 2}, & \gamma_{o 2} r_{\varepsilon 2}, & \alpha_{o 2} r_{\varepsilon 2} \\ & & & & . & & . & & \\ & & & & . & . & & \\ 1, & \gamma_{o 25}, & \alpha_{o 25}, & r_{\varepsilon 25}, & \alpha_{o 25}^{2}, & r_{\varepsilon 25}^{2}, & \gamma_{o 25} \alpha_{o 25}, & \gamma_{o 25} r_{\varepsilon 25}, & \alpha_{o 25} r_{\varepsilon 25}\end{array}\right]$.

According to the orthogonal test scheme of three factor-five level in Table 4, there are three independent experimental factors $\left(\gamma_{o}, \alpha_{o}\right.$, and $\left.r_{\varepsilon}\right)$, so substituting $n=3$ into formula (4), let

$$
\begin{aligned}
& x_{1}=\gamma_{o}, \\
& x_{2}=\alpha_{o}, \\
& x_{3}=r_{\varepsilon}, \\
& \beta_{0}=b_{0}, \\
& \beta_{1}=b_{1}, \\
& \beta_{2}=b_{2}, \\
& \beta_{3}=b_{3}, \\
& \beta_{11}=b_{4}, \\
& \beta_{22}=b_{5}, \\
& \beta_{33}=b_{6}, \\
& \beta_{12}=b_{7}, \\
& \beta_{13}=b_{8} .
\end{aligned}
$$

By replacing the response $\hat{y}$ in formula (4) with the cutting force $\widehat{F}$ and the cutting temperature $\widehat{T}$, the mathematical models between the two responses and tool geometric parameters $\left(\gamma_{o}, \alpha_{o}\right.$, and $\left.r_{\varepsilon}\right)$ can be obtained, respectively, as presented in

$\left\{\begin{array}{l}\widehat{F}=b_{0}+b_{1} \gamma_{o}+b_{2} \alpha_{o}+b_{3} r_{\varepsilon}+b_{4} r_{\varepsilon}^{2}+b_{5} \gamma_{o} \alpha_{o}+b_{6} \gamma_{o} r_{\varepsilon}+b_{7} \alpha_{o} r_{\varepsilon}=\mathbf{x}_{F} \mathbf{b}_{F}, \\ \widehat{T}=b_{0}+b_{1} \gamma_{o}+b_{2} \alpha_{o}+b_{3} r_{\varepsilon}+b_{4} \alpha_{o}^{2}+b_{5} r_{\varepsilon}^{2}+b_{6} \gamma_{o} \alpha_{o}+b_{7} \gamma_{o} r_{\varepsilon}+b_{8} \alpha_{o} r_{\varepsilon}=\mathbf{x}_{T} \mathbf{b}_{T} .\end{array}\right.$

The expressions of 25 groups of cutting forces and temperatures can be obtained by putting 25 groups of orthogonal simulated data in Table 4 into formula (10). Therefore, the four expressions of the column vectors can be written as

$$
\begin{gathered}
\widehat{F}=\left[\begin{array}{c}
F_{1} \\
F_{2} \\
\cdot \\
\cdot \\
\cdot \\
F_{25}
\end{array}\right], \\
\mathbf{b}_{F}=\left[\begin{array}{c}
b_{0} \\
b_{1} \\
\cdot \\
\cdot \\
\cdot \\
b_{7}
\end{array}\right],
\end{gathered}
$$$$
\widehat{T}=\left[\begin{array}{c}
T_{1} \\
T_{2} \\
\cdot \\
\cdot \\
\cdot \\
T_{25}
\end{array}\right] \text {, }
$$

$$
\mathbf{b}_{T}=\left[\begin{array}{c}
b_{0} \\
b_{1} \\
\cdot \\
\cdot \\
b_{8}
\end{array}\right] .
$$

Combining formulas (7) and (8) with (5), matrices are computed with MATLAB programming, and the least square 
estimation of the coefficient matrices $\mathbf{b}_{F}$ and $\mathbf{b}_{T}$ in formula (10) is obtained as follows:

$$
\begin{aligned}
\mathbf{b}_{F} & =\left[\begin{array}{lllllllll}
672 & -3 & -2 & -1851.8 & 24107 & 0 & 27.4 & 21
\end{array}\right]^{\mathrm{T}}, \\
\mathbf{b}_{T} & =\left[\begin{array}{lllllllll}
614 & -1 & -10.1 & 127.5 & 1 & 4407.8 & -0.1 & 25.5 & 0
\end{array}\right]^{\mathrm{T}} .
\end{aligned}
$$

By substituting the two coefficient matrices into formula (10), the mathematical models of the cutting force and the cutting temperature are obtained when tool geometric parameters $\left(\gamma_{o}, \alpha_{o}\right.$, and $\left.r_{\varepsilon}\right)$ are within the range of the values in Table 4.

$$
\left\{\begin{array}{l}
\widehat{F}=672-3 \gamma_{o}-2 \alpha_{o}-1851.8 r_{\varepsilon}+24107 r_{\varepsilon}^{2}+27.4 \gamma_{o} r_{\varepsilon}+21 \alpha_{o} r_{\varepsilon}, \\
\widehat{T}=614-\gamma_{o}-10.1 \alpha_{o}+127.5 r_{\varepsilon}+\alpha_{o}^{2}+4407.8 r_{\varepsilon}^{2}-0.1 \gamma_{o} \alpha_{o}+25.5 \gamma_{o} r_{\varepsilon} .
\end{array}\right.
$$

The prediction results of cutting force and cutting temperature using formula (13) are listed in Table 4. We can see that the prediction results have good agreement with the simulated results when $0^{\circ}<\gamma_{o}<20^{\circ}, 2^{\circ}<a_{o}<10^{\circ}$, and $0.01 \mathrm{~mm}<r_{e}<0.13 \mathrm{~mm}$. The average prediction errors of the cutting force and the cutting temperature are $2.77 \%$ and $4.86 \%$, respectively.

\section{Optimization of Tool Geometric Parameters Using Genetic Algorithm}

The genetic optimization algorithm is used for randomly searching the optimal solution of the objective function by referring natural genetic and selection mechanism in the restricted area. After generating the initial population, according to the principle of "survival of the fittest," successive generations evolve to produce a better improved approximate solution. In each generation, the individual is selected according to the individual fitness in the problem domain, and the population representing the new solution set is produced by implementing the crossover and mutation of the genetic operators of natural genetics. This process will lead to a more environmentally adaptive population than the previous generation. The optimal individuals in the last population can be accepted as approximate optimal solutions after decoding.

The genetic algorithm not only can solve the single objective optimal problem in a given region but also provide a perfect solution to some common multiconstraint and multiobjective optimization problems. Figure 8 is the flow chart of the improved genetic algorithm.

In formula (13), the cutting force and the cutting temperature are two objective functions of the optimization program of the genetic algorithm. For the convenience of description, three independent variables $\gamma_{o}, \alpha_{o}$, and $r_{\varepsilon}$ in formula (13) are expressed with the variables $x_{1}, x_{2}$, and $x_{3}$, and the dependent variables $\widehat{F}$ and $\widehat{T}$ are expressed with $f_{1}$ and $f_{2}$, respectively. Because the cutting force has the different dimension from the cutting temperature, so the objective

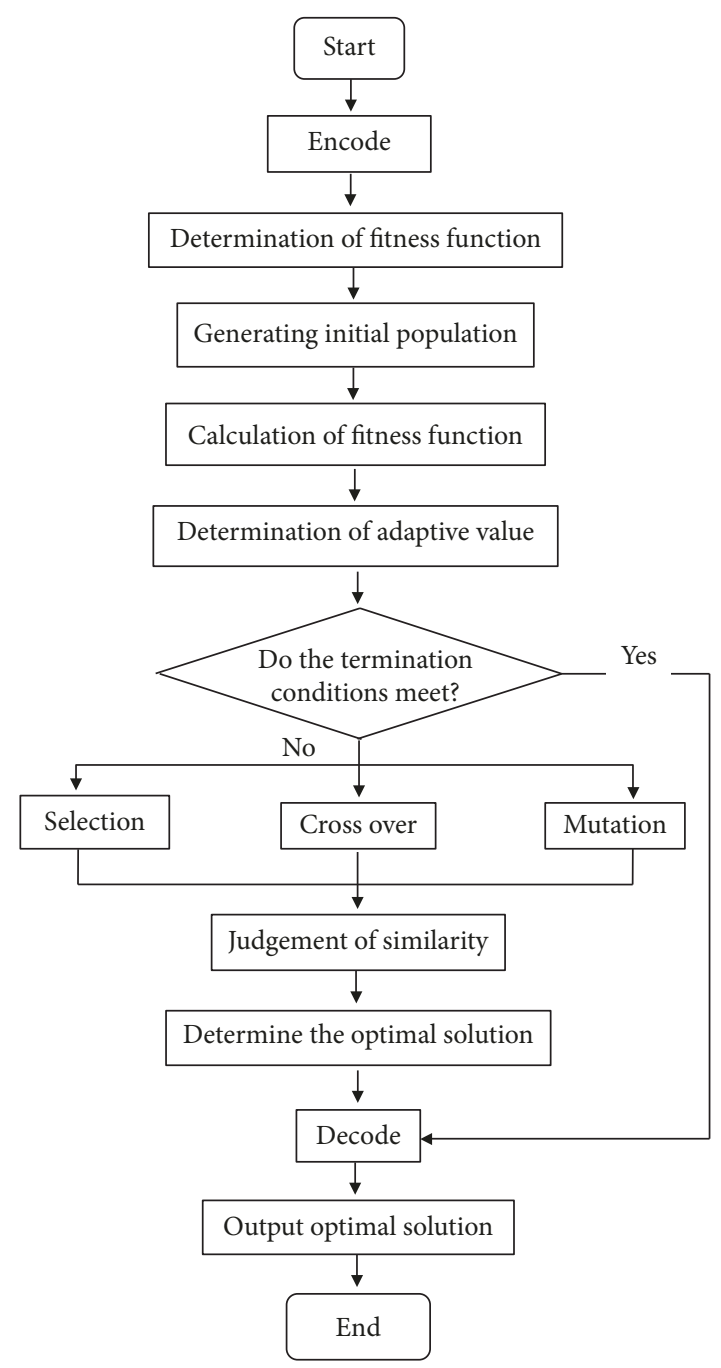

Figure 8: Flow chart of improved genetic algorithm.

functions of parameter optimization are separately expressed in formula (14).

$\begin{cases}\min & f_{1}=672-3 x_{1}-2 x_{2}-1851.8 x_{3}+24107 x_{3}^{2}+27.4 x_{1} x_{3}+21 x_{2} x_{3} \\ \min & f_{2}=614-x_{1}-10.1 x_{2}+127.5 x_{3}+x_{2}^{2}+4407.8 x_{3}^{2}-0.1 x_{1} x_{2}+25.5 x_{1} x_{3}\end{cases}$

The constraint conditions of formula (14) are given with

$$
\text { s.t. }\left\{\begin{array}{l}
0 \leq x_{1} \leq 20 \\
2 \leq x_{2} \leq 10 \\
0.01 \leq x_{3} \leq 0.13
\end{array}\right.
$$

The control parameters of the genetic algorithm have the key effect on the calculation results. They are the population size (NIND), binary encoding length (PRECI), genetic generations (MAXGEN) and generation gap GGAP, and the values are as follows: 
(i) NIND $=25$; $\%$ the number of individuals in the population

(ii) $\mathrm{MAXGEN}=20$; $\%$ maximum genetic generation

(iii) $\mathrm{NVAR}=3$; \% the dimension of variables

(iv) PRECI $=20$; \% binary digits of variables

(v) GGAP $=0.9 ; \%$ generation gap

Among these parameters, NIND directly affects the convergence or computational efficiency of genetic algorithms. Too small size will bring about the convergence to the local optimal solution, and a large number of individuals will result in lower computation speed. Population size is generally selected between 10 and 200 according to the actual situation. The number of individuals in this work is 25 , so $\mathrm{NIND}=25$. There are three independent variables in the objective function; thus, NVAR $=3$. To ensure optimization accuracy, each variable is represented by 20 -bit binary encoding; that is, PRECI $=20$. The size of the generation gap will affect the atavistic heredity of some excellent characteristics of individuals. The possibility of the destruction of the excellent mode in the population will increase if the generation gap is large, and the search will tend to randomize; too small generation gap will make more individuals directly copy to the next generation, and genetic search may fall into a stagnant state; in the optimization process, ensure that $10 \%$ of the most adaptable individuals in each generation will always be transferred to the next generation and $90 \%$ of the new individuals of each generation will be generated. Hence, the generation gap is determined as GGAP $=0.9$.

After the above parameters have been determined, it is found that through running the program, the performance of the optimization result is best traced when the maximum genetic generation is 20. Therefore, MAXGEN $=20$.

In the high-speed machining process, the main factor of tool wear is the high cutting temperature, and the influence of cutting force is relatively weak. So in multiobjective optimization, the different weight coefficients are used; i.e., the weights of $f_{1}$ and $f_{2}$ are taken as 0.3 and 0.7 , respectively. After 20 iterations, the result is $x_{1}=18.5, x_{2}=5.6$, and $x_{3}=0.02$; that is, when the tool rake angle $\gamma_{o}=18.5^{\circ}$, clearance angle $\alpha_{o}=5.6^{\circ}$, and cutting edge radius $r_{\varepsilon}=0.02 \mathrm{~mm}$, the optimal solutions of the cutting force and the temperature under the above weights are $582.76 \mathrm{~N}$ and $573.4^{\circ} \mathrm{C}$, respectively. The performance tracking of the optimization program is shown in Figure 9.

\section{Experimental Verification of High-Speed Cutting Titanium Alloy}

To verify the validity of the genetic algorithm optimization results, grooving experiments are conducted according to the same cutting conditions as the establishment of the mathematical model of cutting force and cutting temperature. The experimental devices are shown in Figures 10(a) and $10(\mathrm{~b})$. Because there is no feed in the axial direction when grooving, so only two force components, namely, the main cutting force $F_{c}$ and the radial thrust force $F_{r}$, are measured.

Experimental details of the machine tools, thermometer, dynamometer, workpiece, and cutting tool are shown in Table 5. The workpiece is the Ti6Al4V cylindrical bar, and its chemical compositions are listed in Table 6.

Figure 11 shows the waveforms of the cutting force and the distribution of cutting temperature field, respectively. It can be seen from Figure 11 that the main cutting force and the thrust force fluctuate periodically, which is related to the formation of saw-tooth chip in high-speed cutting of Ti6Al4V. From Figure 11(b), we can see that during the cutting process, the current maximum temperature of the workpiece surface is $285^{\circ} \mathrm{C}$.

The basic principle of the infrared thermograph uses Stefan-Boltzmann law, as presented in

$$
E=\varepsilon \sigma T^{4}
$$

where $E$ is the radiation energy per unit area of the radiation unit of an object $\left(\mathrm{W} / \mathrm{m}^{2}\right), \varepsilon$ is the radiation coefficient or the surface radiant rate of radiation unit (depending on the surface property of the object; for an absolute black body, $\varepsilon=1), \sigma$ is the Stefan-Boltzmann constant $\left(\sigma=5.76 \times 10^{-8} \mathrm{~W} / \mathrm{m}^{2} \cdot \mathrm{K}^{4}\right)$, and $T$ is the surface temperature $(K)$ of the radiation unit.

The measured temperature with the infrared thermograph is a relative temperature, which lags behind the actual cutting temperature, but the temperature change law and dynamic distribution of the workpiece (or tool) can be obtained based on the heat transfer reverse calculation method.

Using the cutting edge grinder in the laboratory, the carbide cutting tool is ground to meet the requirement according to the optimal tool geometric parameters. Eight groups of repeated experiments are carried out under the same condition, and the experimental results are presented in Table 7. It is found that the errors between the optimal results and the experimentally measured total cutting force and cutting temperature are quite small, and the average errors are about 3\%. This proves the validity of the optimization results. Therefore, the optimized tool geometric parameter values are ideal, and the cutting force and the cutting temperature can be concurrently controlled to the minimum.

\section{Discussion}

Here, we investigate the optimization of cutting-tool's multi geometric parameters (three main tool geometric parameters including rake angle, clearance angle, and cutting edge radius) aiming at multiobjectives (two important physical quantities including cutting force and cutting temperature) in high-speed machining of Ti6Al4V. Therefore, (1) we study the influence laws of single parameter on single objective using finite element simulations first; (2) we combine them to establish the modified functional relations models between three tool geometric parameters and two objectives based on the response surface method (RSM); (3) the models are 


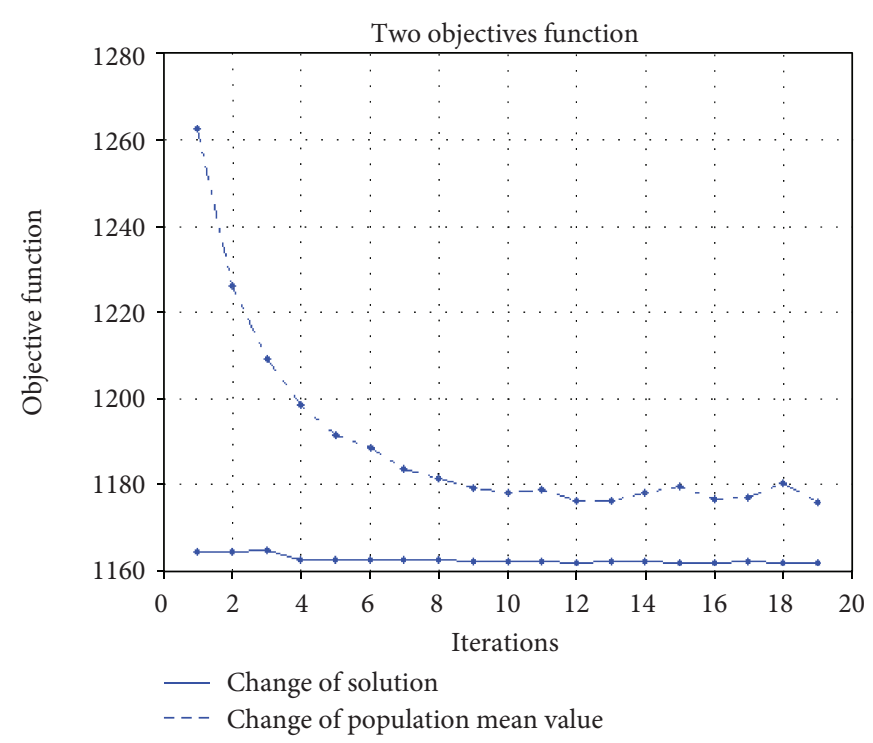

(a)

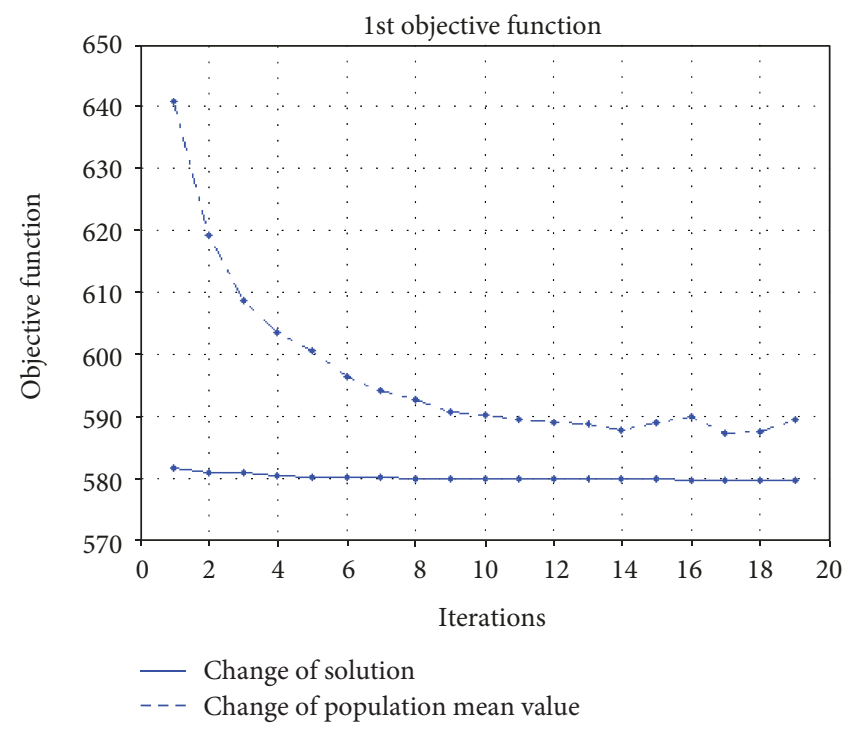

(c)

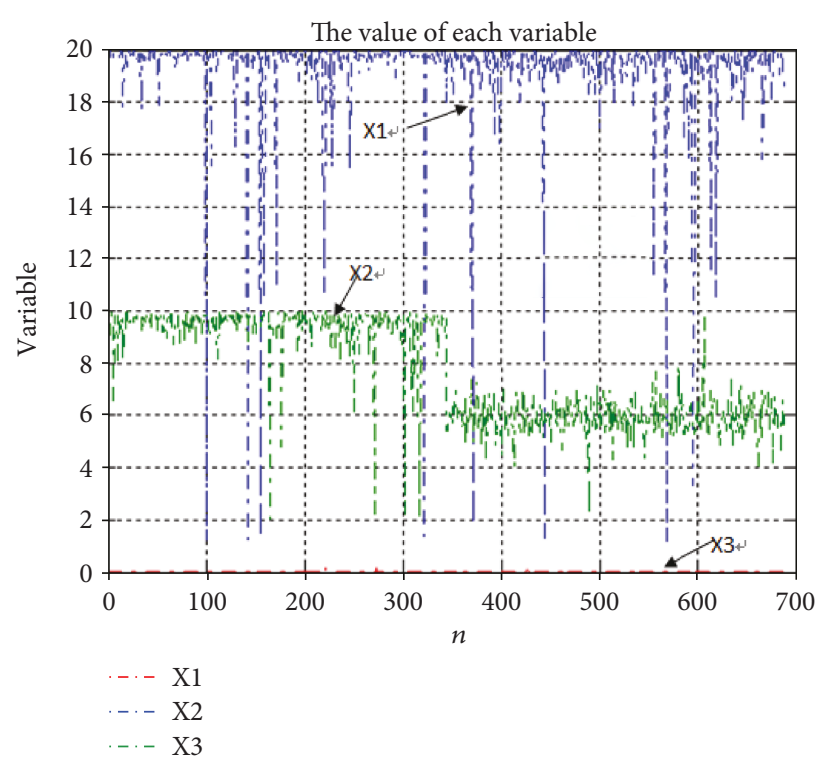

(b)

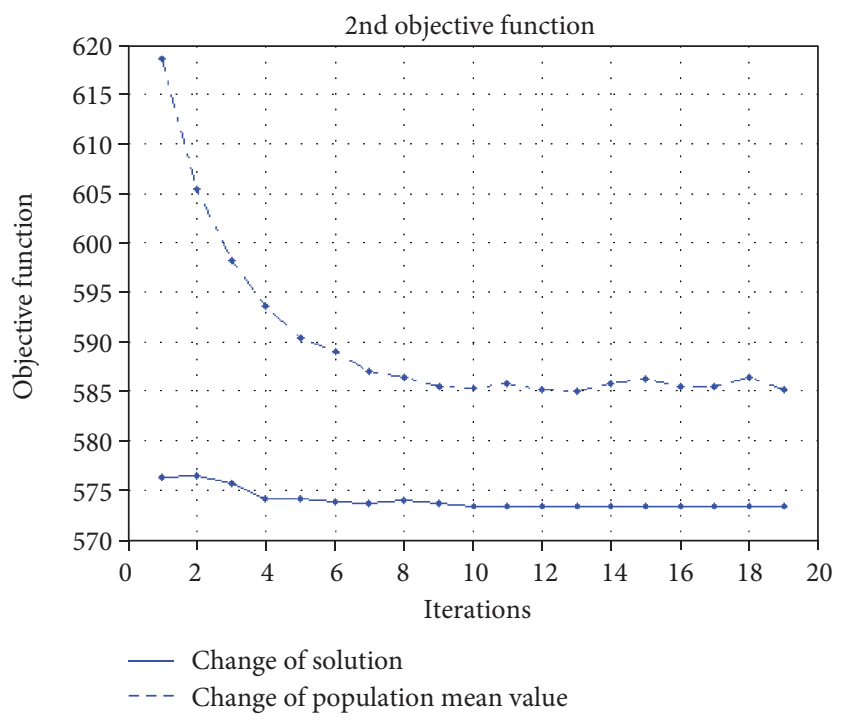

(d)

FIGURE 9: The optimal solution and performance tracking: (a) optimal solution and performance tracking of the sum of two objective functions; (b) optimal solution process diagram; (c) the first objective function; and (d) the second objective function.

solved using the genetic algorithm, and the optimal tool geometric parameter values that can concurrently control the two objectives in their minimum values are obtained. The results show that when the tool rake angle $\gamma_{o}=18.5^{\circ}$, clearance angle $\alpha_{o}=5.6^{\circ}$, and cutting edge radius $r_{\varepsilon}=0.02 \mathrm{~mm}$, the optimal solutions of the cutting force and the cutting temperature are $582.76 \mathrm{~N}$ and $573.4^{\circ} \mathrm{C}$, respectively. These optimal values can ensure both the cutting force and the cutting temperature are not too high. This is very beneficial to the reduction of tool wear.

We conduct finite element simulations of high-speed machining of Ti6Al4V with $0^{\circ}, 5^{\circ}, 10^{\circ}, 15^{\circ}$, and $20^{\circ}$ tool rake angles, and the findings indicate that an increase of the tool rake angle from $10^{\circ}$ to $15^{\circ}$ leads to an obvious decrease of the cutting force, but the increase of the tool rake angle from 15 to $20^{\circ}$ brings about small changes to the physical phenomenon (see Figure 5), which is in accordance with the study of the orthogonal cutting of oxygen-free high conductivity copper (OFHC) by Lo [3]. To reach the goal of reducing the cutting force so as to extend tool life, it is recommended that a tool rake angle of $15^{\circ}$ instead of $20^{\circ}$ be adopted for cutting [3], and the optimum rake angle is $12^{\circ}$ in machining of AISI 1040 steel hardened at HRC 40 by considering the cutting force and temperature together [5], which slightly differs from the optimal value $\gamma_{o}=18.5^{\circ}$ in this work. This is because we go beyond the single rake angle study of [3] and we integrate the cutting temperature into the physical phenomena occurring in the actual metal cutting process besides the cutting force. Furthermore, we study the different 


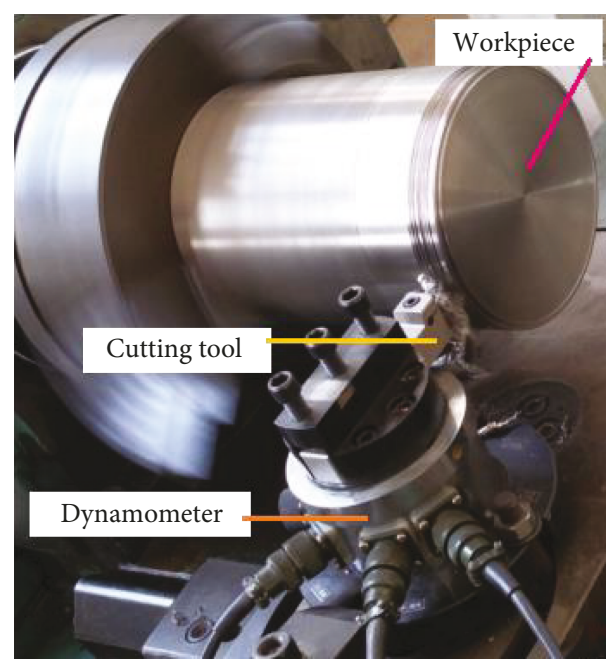

(a)

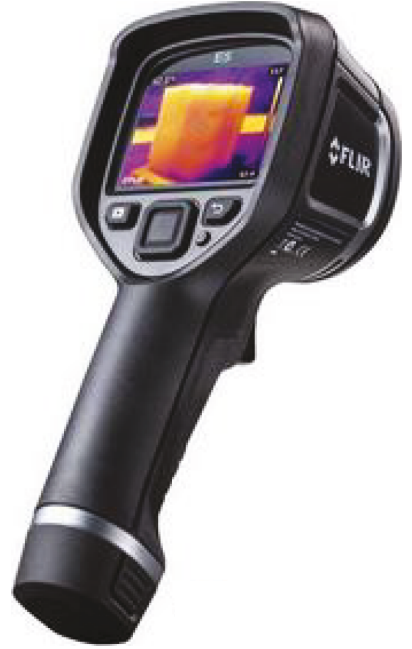

(b)

FIgURE 10: (a) Experimental setup; (b) infrared thermograph FLIR T400.

TABle 5: Experimental specifications and conditions.

\begin{tabular}{|c|c|}
\hline Name & Parameters \\
\hline Lathe CY6140 & $\begin{array}{c}\text { Maximum speed } 1600 \mathrm{rev} / \mathrm{min} \text {; } \\
\text { power } 7.5 \mathrm{~kW}\end{array}$ \\
\hline Dynamometer & BeiHang SDC-C4M \\
\hline $\begin{array}{l}\text { Infrared thermograph } \\
\text { FLIR T400 }\end{array}$ & Measuring range: $-20^{\circ} \mathrm{C}$ to $+1200^{\circ} \mathrm{C}$ \\
\hline Workpiece & $\begin{array}{l}\text { Ti6Al4V material; } \\
\text { diameter } \Phi 150 \mathrm{~mm} \text {; length } 200 \mathrm{~mm}\end{array}$ \\
\hline Cutting condition & $\begin{array}{c}v_{\mathrm{c}}=122.5 \mathrm{~m} / \mathrm{min} ; \text { feed rate } \\
f=0.085 \mathrm{~mm} / \mathrm{rev}\end{array}$ \\
\hline Carbide cutting tool & $\begin{aligned} \gamma_{o}= & 18.5^{\circ} ; \alpha_{o}=5.5^{\circ} ; r_{\varepsilon}=0.02 \mathrm{~mm} ; \\
& \text { cutting edge width } 2 \mathrm{~mm}\end{aligned}$ \\
\hline
\end{tabular}

TABle 6: The chemical compositions of Ti6Al4V.

\begin{tabular}{lcccccc}
\hline Element & $\mathrm{Al}$ & $\mathrm{V}$ & $\mathrm{Ti}$ & $\mathrm{Fe}$ & $\mathrm{C}$ & $\mathrm{N}+\mathrm{O}$ \\
\hline Wt $\%$ & $5.5-6.8$ & $3.5-4.5$ & Balance & 0.30 & 0.10 & 0.57 \\
\hline
\end{tabular}

geometric angles from [5], and the workpiece materials are also different.

With respect to the study of the effect of clearance angle $\alpha_{o}$ on cutting force and cutting temperature, so far, there is no literature available. The reason why our work involves this angle is that it is a crucial angle in metal cutting processes. If the clearance angle equals zero, then the cutting tool may squeeze the workpiece rather than the machining of workpiece.

Regarding the influence of cutting edge radius $r_{\varepsilon}$ on the cutting force in machining titanium alloy, the results show that the cutting force components increase with the increase of rounded cutting edges, which is in line with previous research [4]. And we also have found that total cutting force basically has a quadratic relation with $r_{\varepsilon}$.
At a theoretical level, an important way of our work is that we study the comprehensive effects of tool geometric parameters on physical phenomena of the metal cutting process by means of establishing modified mathematical models according to the dependence of cutting force and cutting temperature on the three tool geometric parameters based on the existing response surface method (RSM) instead of simply using it. This may open the door to future studies aiming at the influence of more tool geometric parameters combining with cutting parameters (cutting speed, feed rate, and depth of cut) on multiphysical phenomena in metal cutting processes.

From an applied perspective, the optimal tool geometric parameter values acquired in our work can be used in the tool design and tool manufacturing for reducing tool wear. It is feasible because the values are verified valid by experiments with the carbide cutting tool, which is ground using a grinder in the laboratory to meet the requirement of the optimal tool geometric parameters values. Moreover, eight groups of repeated experiments are carried out under the same condition. It is found that the errors between the optimal results and the experimentally measured total cutting force and cutting temperature are quite small, and the average errors are about 3\% (see Table 7).

\section{Conclusions}

The conclusions are as follows:

(1) The complex relations between multiparameters and multiobjectives can be studied by investigation of the influence laws of a single parameter on single objective using finite element simulations first and combine them to establish the modified functional relation models between multiparameters and multiobjectives based on the response surface method (RSM) 


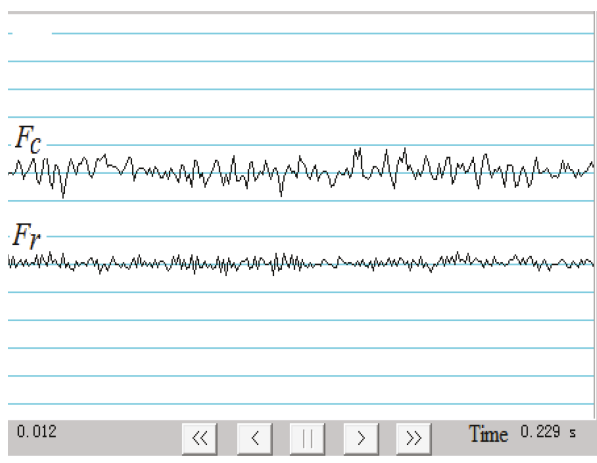

(a)

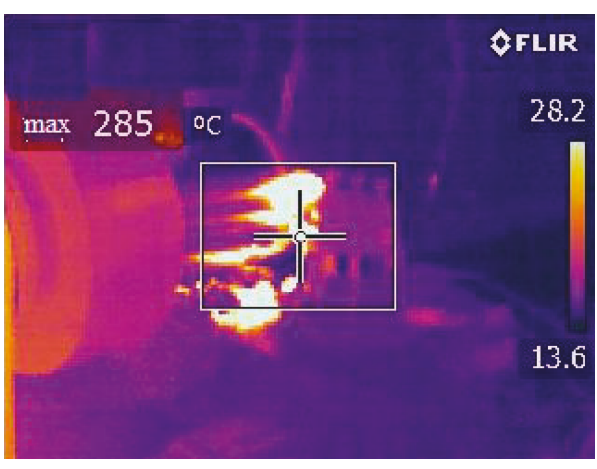

(b)

FIgURE 11: The experimental measurements: (a) cutting force waveform and (b) surface temperature of the workpiece.

TABLE 7: Comparison of the experimentally measured results and the optimal result.

\begin{tabular}{|c|c|c|c|c|c|c|c|c|c|}
\hline No. & 1 & 2 & 3 & 4 & 5 & 6 & 7 & 8 & Average error \% \\
\hline Measured total force $(\mathrm{N})$ & 566.1 & 600.4 & 554 & 594.6 & 599 & 607 & 572 & 597.5 & \\
\hline Optimal force $(\mathrm{N})$ & 582.76 & & & & & & & & \\
\hline Error \% & 2.9 & 3 & 6.7 & 2 & 2.8 & 4.2 & 1.8 & 2.5 & 3.24 \\
\hline Measured temperature $\left({ }^{\circ} \mathrm{C}\right)$ & 570 & 560 & 530 & 602 & 556 & 590 & 582 & 596 & \\
\hline Optimal temperature $\left({ }^{\circ} \mathrm{C}\right)$ & 573.4 & & & & & & & & \\
\hline Error \% & 0.6 & 2.3 & 7.56 & 4.99 & 3.0 & 2.89 & 1.5 & 4.01 & 3.36 \\
\hline
\end{tabular}

(2) Under considering the constraints, the modified functional relation models are solved using the genetic algorithm, and the results show that when the tool rake angle $\gamma_{o}=18.5^{\circ}$, clearance angle $\alpha_{o}=5.6^{\circ}$, and cutting edge radius $r_{\varepsilon}=0.02 \mathrm{~mm}$, the optimal solutions of the cutting force and the cutting temperature are $582.76 \mathrm{~N}$ and $573.4^{\circ} \mathrm{C}$, respectively. These optimal values can ensure both the cutting force and the cutting temperature are not too high. This is very beneficial to the reduction of tool wear

(3) The validity of optimized tool geometric parameter values is verified by experiments, and the optimal results have a good agreement with the experimentally measured total cutting force and cutting temperature, and the average errors are about $3 \%$, indicating that the optimization results are correct and the multiobjective optimization method of multitool geometric parameters in this work is feasible

\section{Data Availability}

The data used to support the findings of this study are included in the article.

\section{Conflicts of Interest}

The authors declare that there are no conflicts of interest regarding the publication of this paper.

\section{Acknowledgments}

This work was supported by the National Natural Science Foundation of China (grant number 61562055).

\section{References}

[1] X. Ai, Z. Q. Liu, C. Z. Huang, J. X. Deng, and J. Zhao, "Synthetic technology research on high speed cutting," Aeronautical Manufacturing Technology, vol. 3, pp. 20-23, 2002.

[2] B. Denkena and D. Biermann, "Cutting edge geometries," CIRP Annals, vol. 63, no. 2, pp. 631-653, 2014.

[3] S.-P. Lo, "An analysis of cutting under different rake angles using the finite element method," Journal of Materials Processing Technology, vol. 105, no. 1-2, pp. 143-151, 2000.

[4] C. F. Wyen and K. Wegener, "Influence of cutting edge radius on cutting forces in machining titanium," CIRP Annals, vol. 59, no. 1, pp. 93-96, 2010.

[5] H. Saglam, F. Unsacar, and S. Yaldiz, "Investigation of the effect of rake angle and approaching angle on main cutting force and tool tip temperature," International Journal of Machine Tools and Manufacture, vol. 46, no. 2, pp. 132-141, 2006.

[6] A. A. Sultan and A. C. Okafor, "Effects of geometric parameters of wavy-edge bull-nose helical end-mill on cutting force prediction in end-milling of Inconel 718 under MQL cooling strategy," Journal of Manufacturing Processes, vol. 23, pp. 102-114, 2016.

[7] R. Kountanya, I. Al-Zkeri, and T. Altan, "Effect of tool edge geometry and cutting conditions on experimental and simulated chip morphology in orthogonal hard turning of $100 \mathrm{Cr} 6$ 
steel," Journal of Materials Processing Technology, vol. 209, no. 11, pp. 5068-5076, 2009.

[8] K. D. Bouzakis, E. Bouzakis, S. Kombogiannis et al., "Effect of cutting edge preparation of coated tools on their performance in milling various materials," CIRP Journal of Manufacturing Science and Technology, vol. 7, no. 3, pp. 264-273, 2014.

[9] Y. Z. Pan, X. Ai, Z. T. Tang, and J. Zhao, "Optimization of tool geometry and cutting parameters based on a predictive model of cutting force," China Mechanical Engineering, vol. 4, no. 4, pp. 428-431, 2008.

[10] M. Wan, J. Feng, W. H. Zhang, Y. Yang, and Y. C. Ma, "Working mechanism of helix angle on peak cutting forces together with its design theory for peripheral milling tools," Journal of Materials Processing Technology, vol. 249, pp. 570-580, 2017.

[11] M. Mia, M. A. Bashir, M. A. Khan, and N. R. Dhar, "Optimization of MQL flow rate for minimum cutting force and surface roughness in end milling of hardened steel (HRC 40)," The International Journal of Advanced Manufacturing Technology, vol. 89, no. 1-4, pp. 675-690, 2017.

[12] N. Narutaki, "High-speed machining of titanium alloy," Chinese Journal of Mechanical Engineering, vol. 15, pp. 109113, 2002.

[13] N. A. Abukhshim, P. T. Mativenga, and M. A. Sheikh, "Heat generation and temperature prediction in metal cutting: a review and implications for high speed machining," International Journal of Machine Tools \& Manufacture, vol. 46, no. 7-8, pp. 782-800, 2006.

[14] F. L. Jiang, Z. Q. Liu, Y. Wan, and Z. Y. Shi, "Analytical modeling and experimental investigation of tool and workpiece temperatures for interrupted cutting 1045 steel by inverse heat conduction method," Journal of Materials Processing Technology, vol. 213, no. 6, pp. 887-894, 2013.

[15] J. Xie, M. J. Luo, K. K. Wu, L. F. Yang, and D. H. Li, "Experimental study on cutting temperature and cutting force in dry turning of titanium alloy using a non-coated micro-grooved tool," International Journal of Machine Tools \& Manufacture, vol. 73, pp. 25-36, 2013.

[16] M. C. Shaw, Metal Cutting Principles, Oxford University Press, Oxford, 1991.

[17] W. S. Lee and C. F. Lin, "High-temperature deformation behaviour of Ti6Al4V alloy evaluated by high strain-rate compression tests," Journal of Materials Processing Technology, vol. 75, no. 1-3, pp. 127-136, 1998.

[18] J. Sun and Y. B. Guo, "Material flow stress and failure in multiscale machining titanium alloy Ti-6Al-4V," International Journal of Advanced Manufacturing Technology, vol. 41, no. 7-8, pp. 651-659, 2009.

[19] T. H. C. Childs, M. H. Dirikolu, and K. Maekawa, "Modelling of friction in the simulation of metal machining," Tribology Series, vol. 34, pp. 337-346, 1998.

[20] T. Ozel, "The influence of friction models on finite element simulations of machining," International Journal of Machine Tools and Manufacture, vol. 46, no. 5, pp. 518-530, 2006. 


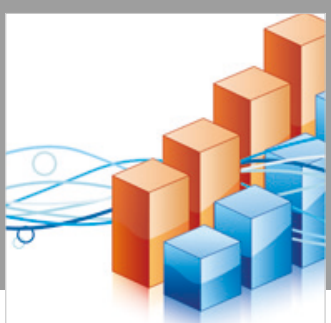

Advances in

Operations Research

\section{-n-m}
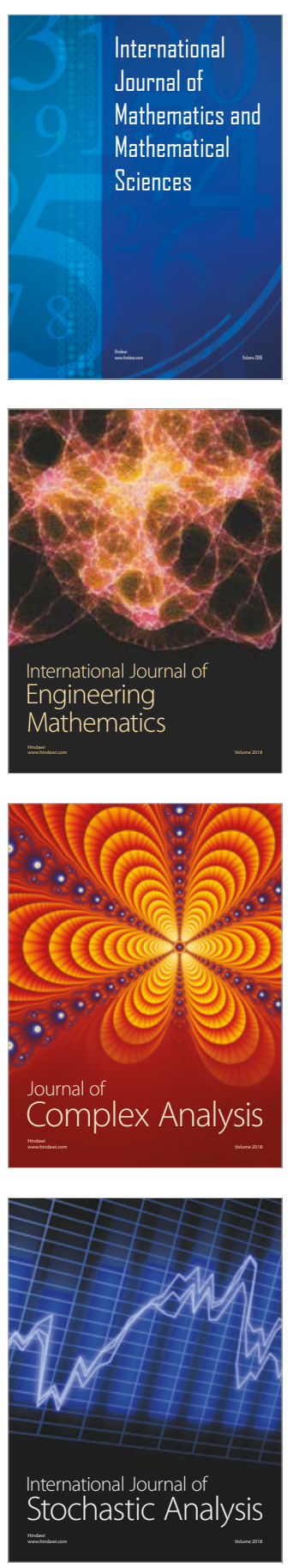
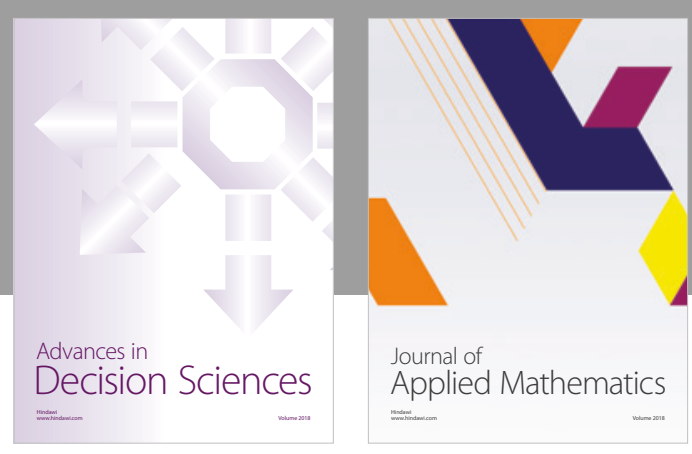

Journal of

Applied Mathematics
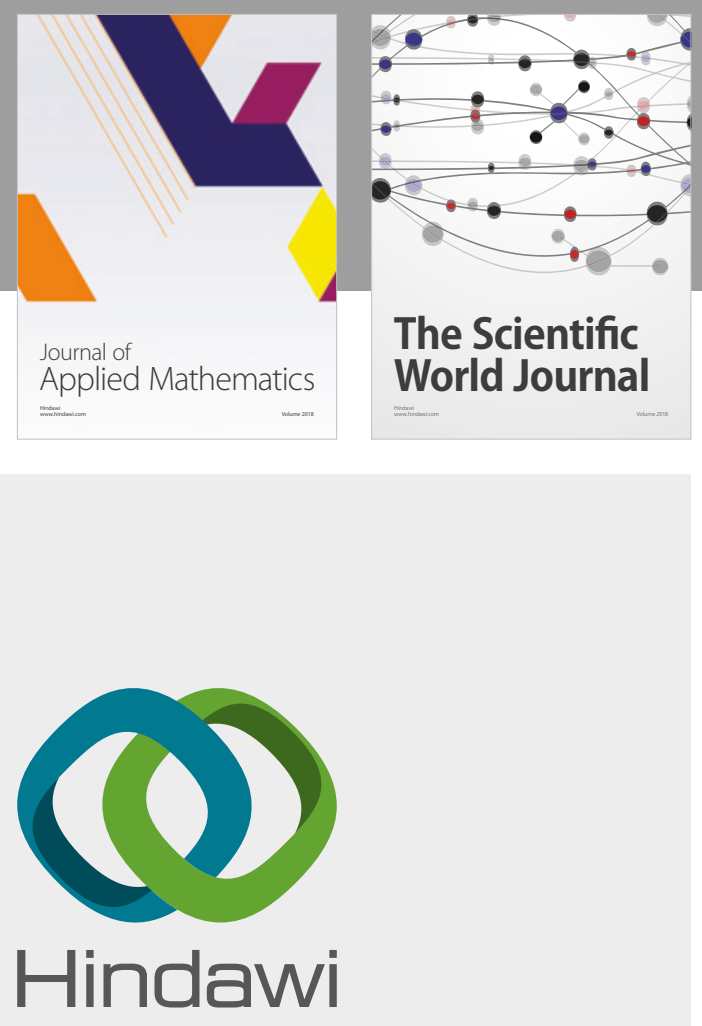

Submit your manuscripts at

www.hindawi.com

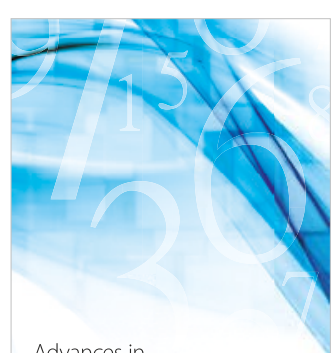

Advances in
Numerical Analysis
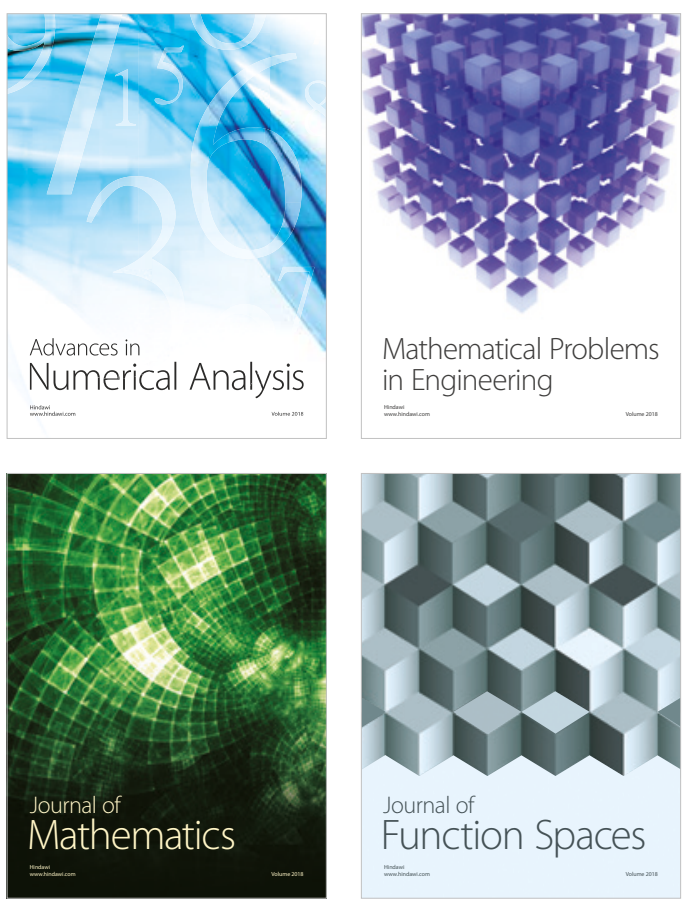

Mathematical Problems in Engineering

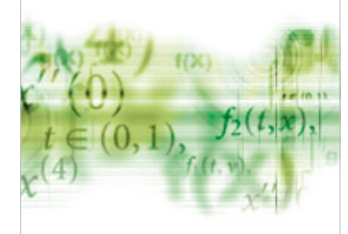

International Journal of

Differential Equations

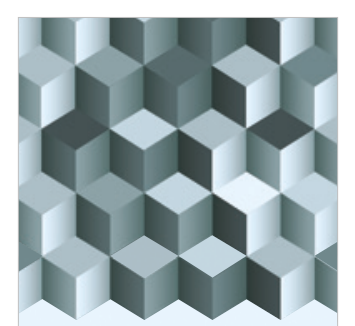

Journal of

Function Spaces
The Scientific

World Journal

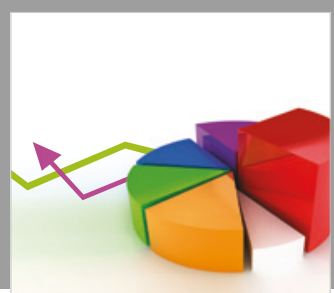

Journal of

Probability and Statistics
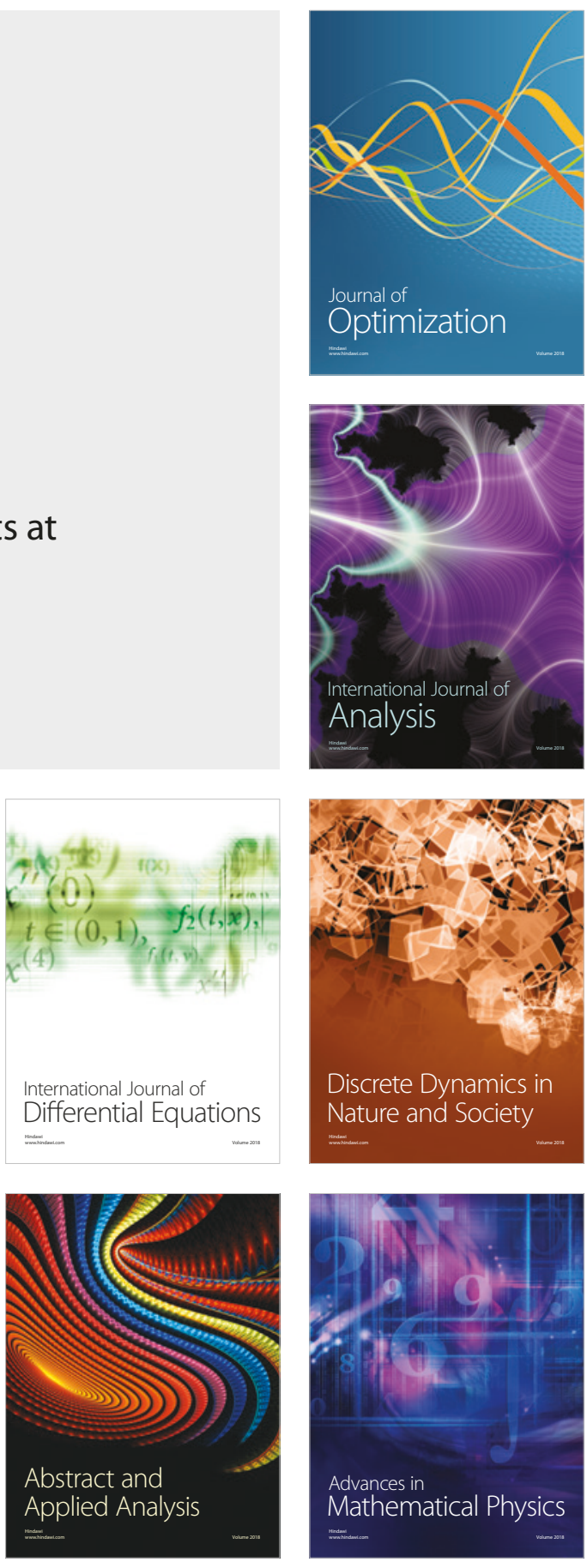